\title{
Slitine s prisjetljivosti oblika (I. dio): najznačajnija svojstva
}

\author{
I. Ivanić,, M. Gojić i S. Kožuh
}

Metalurški fakultet, Sveučilište u Zagrebu, Aleja narodnih heroja 3, 44103 Sisak, Hrvatska

\begin{abstract}
U ovom radu naveden je pregled termomehaničkih svojstava slitina s prisjetljivosti oblika i opća obilježja martenzitne transformacije. Slitine s prisjetljivosti oblika pripadaju skupini relativno novih metalnih materijala te se od drugih slitina (npr. dentalnih slitina) razlikuju po pseudoelastičnosti i efektu prisjetljivosti oblika. Pseudoelastičnost je povezana s nastankom martenzita transformacijom austenita. Austenitno-martenzitna transformacija može se inducirati mehaničkim (naprezanje) ili toplinskim (zagrijavanje i hlađenje) metodama. Tijekom martenzitne transformacije ne odvijaju se procesi difuzije, nego dolazi do neelastične deformacije kristalne strukture. Austenitno-martenzitnu transformaciju karakteriziraju temperature početka te završetka austenitne i martenzitne transformacije $\left(A_{\mathrm{s}}\right.$ i $A_{\mathrm{f}}, M_{\mathrm{s}}$ i $\left.M_{\mathrm{f}}\right)$. Također su detaljno objašnjeni jednosmjerni, dvosmjerni i višestruki efekt prisjetljivosti oblika, te je uočeno da je jednosmjerni efekt prisjetljivosti oblika još uvijek najčešće primjenjivan efekt.
\end{abstract}

Ključne riječi: Slitine s prisjetljivosti oblika, martenzitna transformacija, austenit, pseudoelastičnost, efekt prisjetljivosti oblika

\section{Uvod}

Termin slitine s prisjetljivosti oblika (SMA) primjenjuje se na grupu metalnih materijala koji pokazuju sposobnost vraćanja u njihovo prethodno definirano stanje ili oblik, pri određenom postupku toplinske obrade. Navedeni materijali mogu se plastično deformirati na relativno niskim temperaturama te se nakon izloženosti višim temperaturama vraćaju u oblik prije deformacije. Promjena oblika posljedica je austenitno-martenzitne transformacije u strukturi slitine. Cjelokupni ciklus austenitno-martenzitne transformacije karakteriziraju sljedeće temperature: $A_{\mathrm{s}}$ - temperatura početka austenitne transformacije, $A_{f}$ - temperatura završetka austenitne transformacije, $M_{\mathrm{s}}$ - temperatura početka martenzitne transformacije i $M_{f}$ - temperatura završetka martenzitne transformacije.

Efekt prisjetljivosti oblika uočio je švedski istraživač Ölander 1932. godine, na slitini zlata i kadmija, kod koje se pokazalo da martenzitna faza može poprimiti oblik koji se s promjenom temperature mijenja. Veća pažnja počela se posvećivati ovoj pojavi kada su Buehler i suradnici otkrili efekt prisjetljivosti oblika u slitini nikla i titanija. ${ }^{1-7}$

Nedugo nakon toga dolazi do većeg zanimanja za istraživanja navedenih slitina. Postoji velik broj slitina koje posjeduju efekt prisjetljivosti oblika, a to su slitine na bazi nikla (NiTi, NiMnGa), slitine na bazi bakra (Cu-Zn-X $(X=\mathrm{Al}$, Si, Sn, Ga, Mn), Cu-Al-X (X = Ni, Be, Zn, Mn), Cu-Zn-Al-X $(X=N i, M n)$, slitine na bazi željeza (Fe-Mn, FePt, FeMnSi, FeCoNiTi) i slitine na bazi plemenitih metala (AuCd, AuAg, PtAl, PtTi, PtGa). ${ }^{8}$

\footnotetext{
*Autor za dopisivanje: Ivana Ivanić, mag. ing. met. e-pošta: iivanic@simet.hr
}

Kao posljedica martenzitne transformacije u strukturi homogene tvari javljaju se karakteristične pojave u slitinama s prisjetljivosti oblika, a to su pseudoelastičnost, efekt prisjetljivosti oblika i tzv. "rubber-like" ponašanje, koje određuju uvjete primjene pojedine vrste slitina s prisjetljivosti oblika. ${ }^{6,7}$

Cilj je rada pregledno prikazati termomehanička svojstva slitina s prisjetljivosti oblika, primarno pseudoelastičnost i efekt prisjetljivosti oblika (jednosmjerni i dvosmjerni efekt) te opća obilježja martenzitne transformacije.

\section{Martenzitna transformacija}

Ključna transformacija odgovorna za ponašanje slitina s prisjetljivosti oblika je martenzitna transformacija. Martenzitna transformacija je povratni kristalografski reorijentacijski proces između dviju stabilnih faza. Transformacija se zbiva kada Gibbsova energija martenzita postaje niža od Gibbsove energije austenita pri temperaturi ispod kritične temperature $t_{0}$, koja predstavlja temperaturu termodinamičke ravnoteže pri kojoj su Gibbsove energije obaju faza jednake. ${ }^{6,7}$

Ponašanje slitina s prisjetljivosti oblika znatno je kompleksnije od uobičajenih materijala. Njihova upotreba zahtijeva jedinstvena svojstva, a to su pseudoelastičnost i efekt prisjetljivosti oblika, koji su posljedica fazne transformacije austenita u martenzit. ${ }^{-5,9,10}$

Dvije faze najznačajnije za slitine s prisjetljivosti oblika su: austenit - A (stabilan na višim temperaturama) i martenzit - M (stabilan na nižim temperaturama). Navedene faze razlikuju se u kristalnim strukturama. $U$ odnosu na kristalno zrno austenitne faze moguće je nastajanje šest skupina martenzitnih pločica s po četiri međusobno različite orijentacije martenzita, tj. ukupno su moguće 24 varijante martenzita. Morfologija martenzita može biti samoprilagođavajuća ili 
naprezanjem inducirana, a martenzitna faza nastaje u obliku tankih pločica, iglica ili štapića s dobro definiranom kristalnom orijentacijom u odnosu na kristal početne austenitne faze. ${ }^{11}$

Za samoprilagođavajuću morfologiju martenzita potrebni su sljedeći uvjeti:

- geometrijski (prisutnost najmanje dviju varijanti martenzita)

- makroskopski (komponente deformacije osnove slitine svesti na minimum)

- mikroskopski (nastajanje kristalografski povoljnih, koherentnih ravnina između martenzitnih varijanti). ${ }^{2}$

Austenit i samoprilagođavajući martenzit mogu koegzistirati tijekom toplinskih ciklusa bez naprezanja. Veze između austenita, samoprilagođavajućeg martenzita i martenzita induciranog naprezanjem i šest mogućih transformacija između njih su sljedeće (slika 1):

1. austenit se transformira u naprezanjem induciran martenzit pod djelovanjem naprezanja $(A \rightarrow D M)$

2. naprezanjem induciran martenzit transformira se povratno $\mathrm{u}$ austenit nakon rasterećenja na visokim temperaturama $(\mathrm{DM} \rightarrow \mathrm{A})$

3. naprezanjem inducirani martenzit (varijanta k) transformira se u drugi naprezanjem inducirani martenzit (varijanta I) pri određenom naprezanju $\left(\mathrm{DM}_{\mathrm{k}} \rightarrow \mathrm{DM}_{\mathrm{l}}\right)$

4. samoprilagođavajući matrenzit transformira se u naprezanjem induciran martenzit pri određenom naprezanju $(\mathrm{TM} \rightarrow \mathrm{DM})$

5. austenit se transformira u naprezanjem induciran martenzit pri naprezanju $(A \rightarrow D M)$

6. samoprilagođavajući martenzit se transformira u austenit pri zagrijavanju $(\mathrm{TM} \rightarrow \mathrm{A}) .^{12}$

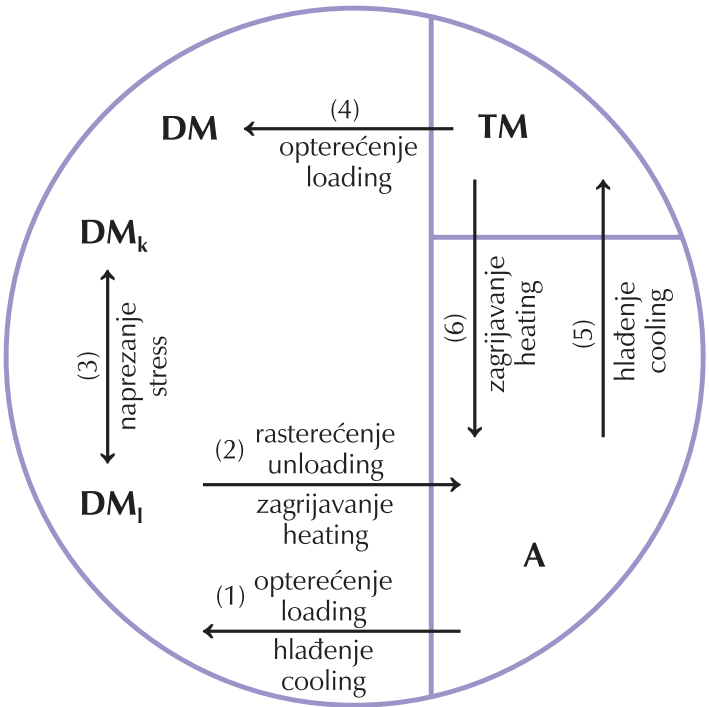

SIi ka 1 - Shematski prikaz šest faznih transformacija slitina s prisjetljivosti oblika, gdje su: A - austenit, TM - samoprilagođavajući martenzit, DM - naprezanjem inducirani martenzit, $D M_{\mathrm{k}}$ - naprezanjem inducirani martenzit (varijanta k) i DM - naprezanjem inducirani martenzit (varijanta l) ${ }^{12}$

F i g . 1 - Schematic illustration of six phase transformations of shape memory alloys, where: A - austenite, TM selfaccommodating martensite, DM - stress induced martensite, $D M_{\mathrm{k}}$ - stress induced martensite (variant k) and $D M_{1}-$ stress induced martensite (variant l) ${ }^{12}$
Cjelokupni ciklus transformacije karakteriziran je temperaturama $A_{\mathrm{s}} A_{\mathrm{f}}, M_{\mathrm{s}}$ i $M_{\mathrm{f}}$. Tijekom transformacija $\mathrm{A} \rightarrow \mathrm{M}$ i $\mathrm{M} \rightarrow$ A dolazi do pojave temperaturne histereze, jer se transformacije koje se odvijaju zagrijavanjem i hlađenjem slitine ne odvijaju na istim temperaturama, slika $2 .{ }^{13}$

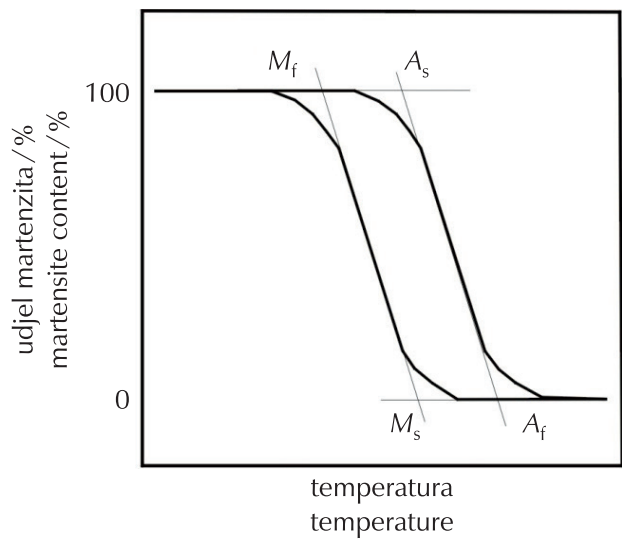

S I i ka 2 - Shematski prikaz temperaturne histereze i karakterističnih temperatura martenzitne transformacije ${ }^{13}$

F i g . 2 - Schematic representation of the temperature hysteresis loop and characteristic temperatures of martensitic transformation ${ }^{13}$

Poznato je da se transformacija zbiva kada Gibbsova energija martenzita postaje niža od Gibbsove energije austenita pri temperaturi ispod kritične temperature $\left(t_{0}\right)$, slika 3. Međutim, martenzit ne nastaje točno na temperaturi $t_{0}$, ako nije na slitinu primijenjeno naprezanje, nego na temperaturi $M_{\mathrm{s}}$ (temperatura početka stvaranja martenzita) koja je niža od $t_{0}$. Promjena slobodne energije $\Delta G^{\mathrm{p} \rightarrow \mathrm{m}}=G^{\mathrm{m}}-G^{\mathrm{p}}$ predstavlja pokretačku snagu za nukleaciju martenzita, dok su $G^{\mathrm{m}} \mathrm{i}$ $G^{p}$ Gibbsove slobodne energije za martenzitnu i austenitnu fazu. Kada se slitina zagrijava iz područja martenzitne faze, ne primjenjujući naprezanje, povratna transformacija (martenzit $\rightarrow$ austenit) započinje pri temperaturi $A_{\mathrm{s}}$, koja je viša od $t_{0}$. Prema literaturnim podacima ${ }^{6,7,14}$ kritična temperatura $\left(t_{0}\right)$ može se prikazati kao $t_{0}=\left(M_{\mathrm{s}}+A_{\mathrm{s}}\right) / 2$.

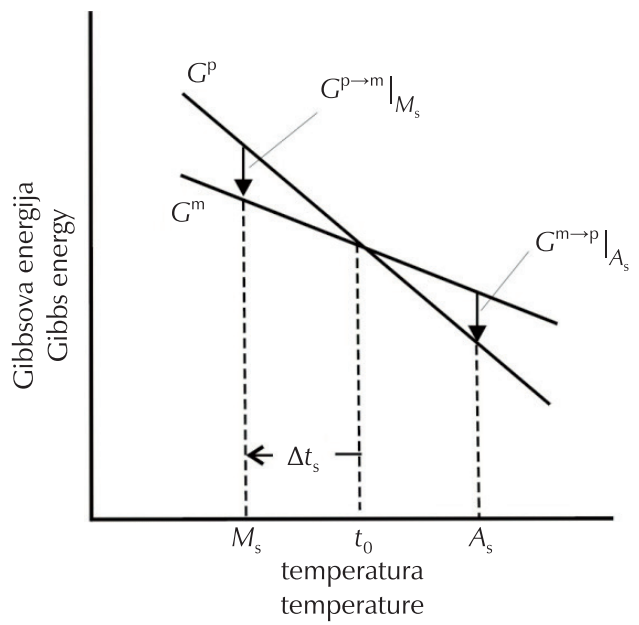

S I i k a 3 -Shematski prikaz Gibbsove energije austenitne i martenzitne faze te njihova ovisnost o temperaturi $\mathrm{M}_{\mathrm{s}} i$ $\mathrm{A}_{\mathrm{s}} . \Delta \mathrm{t}_{\mathrm{s}}$ je pothlađenje potrebno za transformaciju. ${ }^{6,7}$

Fig. 3 - Schematic representation of Gibbs energy for both austenite and martensite phases, and their relation to the $\mathrm{M}_{\mathrm{s}}$ and $\mathrm{A}_{\mathrm{s}}$ temperatures. $\Delta \mathrm{t}_{\mathrm{s}}$ is the supercooling required for the transformation. ${ }^{6,7}$ 
Za slitine s prisjetljivosti oblika temperature faznih transformacija $\left(M_{\mathrm{s}}, M_{\mathrm{f}}, A_{\mathrm{s}}, A_{\mathrm{f}}\right)$ te razlike $M_{\mathrm{s}}-M_{\mathrm{f}}$ i $A_{\mathrm{f}}-A_{\mathrm{s}}$ vrlo su važni čimbenici za karakterizaciju ponašanja slitine. Temperature faznih transformacija najviše ovise o kemijskom sastavu i procesu proizvodnje slitine. Međutim mikrostrukturni defekti, stupanj uređenja osnovne faze i veličina zrna osnovne faze također mogu promijeniti temperature faznih transformacija. ${ }^{14}$ Osnovni faktori koji utječu na temperaturu transformacija slitine s prisjetljivosti oblika su kemijski sastav slitine te postupak toplinske obrade, brzina hlađenja, veličina zrna i broj transformacijskih ciklusa. ${ }^{6}$

Tijekom fazne transformacije mijenja se nekoliko fizikalnih svojstava materijala. Primjerice latentna toplina transformacije ovisi o smjeru transformacije (energija se dovodi ili oslobađa). Transformacija austenita u martenzit povezana je s oslobađanjem topline (egzotermna fazna transformacija). Povratna transformacija martenzita u austenit povezana je s dovođenjem energije za odvijanje reakcije (endotermna fazna transformacija).

Kada slitina s prisjetljivosti oblika prolazi kroz faznu transformaciju, ona se transformira iz faze visoke uređenosti (austenitne faze) u fazu niske uređenosti (martenzitnu fazu). Početna faza je austenitna $\beta$-faza (slika 4a). U izostanku primijenjenog naprezanja pločice martenzita nastaju spontano, srasčivanjem ili klizanjem (slika 4b), pri čemu nema promjene oblika. Pri mehaničkom opterećenju martenzitne pločice se reorijentiraju (slika 4c), te nastaje makroskopski gledano neelastično istezanje, gdje je dominantna varijanta A martenzita nastala u smjeru primijenjenog naprezanja. Nakon zagrijavanja iznad određene temperature odvija se transformacija martenzita u austenit te dolazi do nestanka deformacije. ${ }^{1,5,11}$

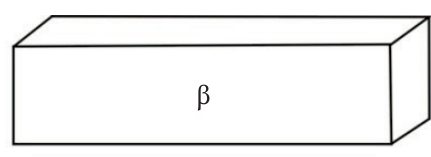

(a) $t>A_{i}$

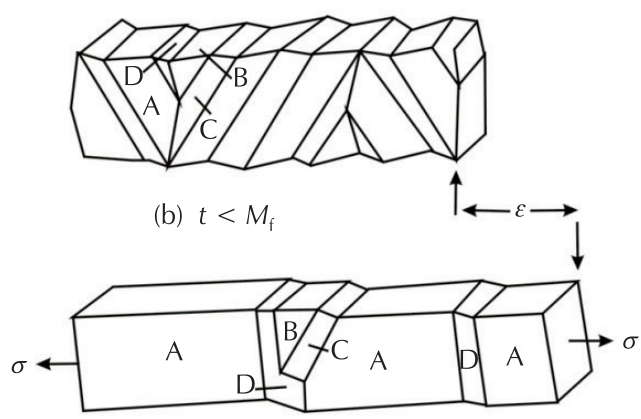

(c) $t<M_{\mathrm{f}}$

SI i ka 4 -Shematski prikaz kristala $\beta$-faze (a), spontano nastali martenzit, sraslačke varijante $A, B, C$ i $D$ nakon hlađenja i transformacije u martenzit (b), varijanta $A$ je dominantna nakon podvrgavanja naprezanju (c) ${ }^{1,5}$

F i g . 4 -Schematic illustration of a $\beta$ phase crystal (a), self-accommodating, twin-related variants $A, B, C$ and $D$, after cooling and transformation to martensite (b), variant $\mathrm{A}$ becomes dominant when stress is applied (c) $)^{1,5}$

\section{Termomehaničko ponašanje slitina s prisjetljivosti oblika}

Slitine s prisjetljivosti oblika karakterizira nekoliko specifičnih pojava poput pseudoelastičnosti, superelastičnosti, efekta prisjetljivosti oblika i tzv. ponašanje "rubber-like". 6,7,14 Dva su najvažnija oblika termomehaničkog ponašanja slitina s prisjetljivosti oblika - pseudoelastičnost i efekt prisjetljivosti oblika.

\section{Pseudoelastičnost}

Pseudoelastičnost je pojava nastajanja martenzitne faze primjenom termomehaničkog opterećenja tijekom kojeg iz austenitne faze nastaje naprezanjem inducirani martenzit pri konstantnoj temperaturi. Proces je povezan sa znatnom neelastičnom deformacijom, koja nestaje nakon rasterećenja, odnosno martenzitno-austenitne transformacije.

Pseudoelastičnost se odvija na temperaturama iznad temperature $A_{\mathrm{f}}, \mathrm{tj}$. u području gdje je austenitna faza stabilna. Mehaničkim ispitivanjem na konstantnoj temperaturi iznad $A_{\mathrm{f}}$ dobiva se dijagram naprezanje - deformacija koji prikazuje makroskopsko ponašanje pseudoelastičnosti kod slitina s prisjetljivosti oblika, slika 5. ${ }^{3}$ Tijekom mehaničkog ispitivanja u uzorku se javlja elastična deformacija dok se ne dostigne kritična vrijednost do točke A. Tada se odvija martenzitna transformacija (austenit $\rightarrow$ martenzit), tj. povećava se udjel martenzita, te transformacija završava u točki B. U točki B mikrostruktura se u potpunosti sastoji od martenzita induciranog naprezanjem. Tijekom procesa rasterećenja, slitina se elastično oporavlja (B $\rightarrow \mathrm{C}$ ). Od točke $\mathrm{C} \rightarrow \mathrm{D}$ mikrostruktura slitine transformira se iz martenzita u austenit. Kada je proces ispitivanja gotov, slitina nema zaostalog istezanja. ${ }^{1,3,5}$
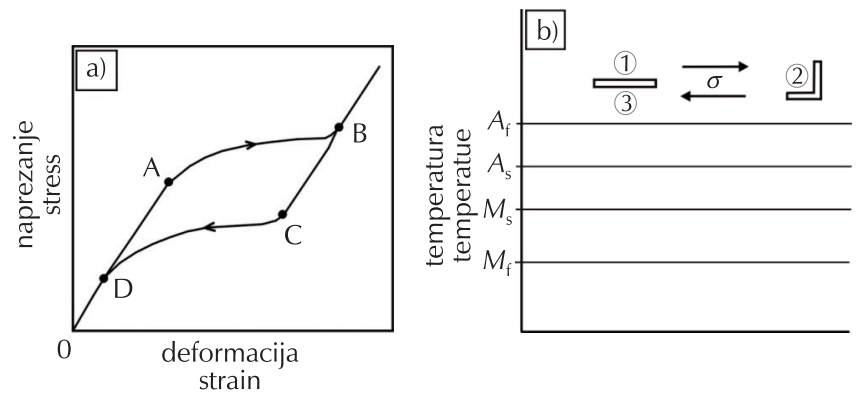

S I i k a 5 -Dijagram naprezanje-deformacija slitine s prisjetljivosti oblika (a) i shematski prikaz pseudoelastičnosti (b), gdje 1 i 3 prikazuju početni oblik slitine i 2 prikazuje oblik slitine nakon deformacije ${ }^{3}$

F i g . 5 - Stress - strain curve of shape memory alloy (a) and schematic illustration of pseudoelasticity (b), where 1 and 3 show the original shape of the alloy and 2 shows shape of the alloy after deformation ${ }^{3}$

\section{Efekt prisjetljivosti oblika}

Drugi oblik termomehaničkog ponašanja slitina s prisjetljivosti oblika je efekt prisjetljivosti oblika. Termin efekt prisjetljivosti oblika u početku je upotrebljavan za pojavu oporavka oblika koji je primijećen u nekim slitinama. U svim materijalima s prisjetljivosti oblika trenutačni oblik dobiva se određenim postupkom, tj. toplinskom ili termomehaničkom obradom (tzv. "trening" ili programiranje slitine). Najpoznatija metoda programiranja je deformiranje na povišenim 
temperaturama, iznad temperature $A_{f}$, zatim hlađenje na sobnu temperaturu, pri čemu je slitina konstantno podvrgnuta naprezanju. ${ }^{14,15}$

\section{Jednosmjerni efekt prisjetljivosti oblika}

Kada se uzorak podvrgne mehaničkom opterećenju, naprezanje dosegne kritičnu vrijednost do točke A, slika 6. Tada započinje transformacija samoprilagođavajućeg martenzita u deformacijski induciranom martenzitu, te završava u točki B. Kada proces opterećenje - rasterećenje završi, slitina zadržava određeno istezanje, tj. određeni oblik (točka C). To zaostalo istezanje može se oporaviti zagrijavanjem slitine te se inducira povratna fazna transformacija. Ovaj efekt je poznat i kao jednosmjerni efekt prisjetljivosti oblika. ${ }^{3}$
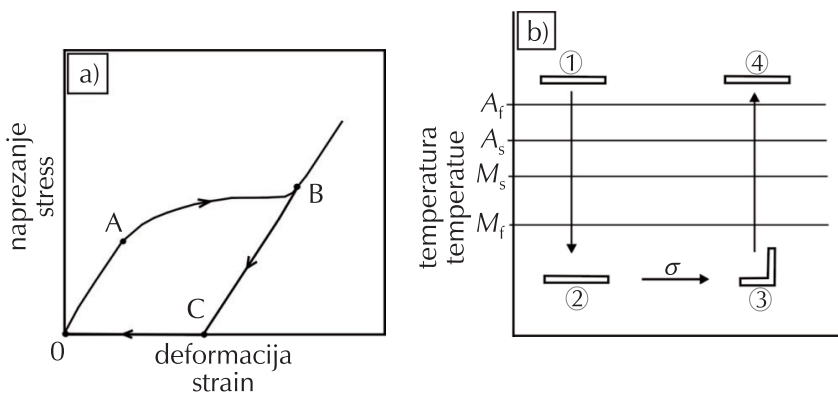

S I i k a 6 -Dijagram naprezanje-deformacija za slitinu s prisjetljivosti oblika (a) i shematski prikaz jednosmjernog efekta prisjetljivosti oblika (b), gdje 1 i 4 prikazuju izvorni oblik slitine, 2 prikazuje oblik nakon hlađenja i 3 prikazuje oblik slitine nakon naprezanja ${ }^{3}$

F i g . 6 - Stress - strain curve for shape memory alloy (a) and schematic illustration of one-way shape memory effect (b), where 1 and 4 show original shape of the alloy, 2 shows shape after cooling, and 3 shows the shape of the alloy after applied stress ${ }^{3}$

U literaturi ${ }^{16,17}$ je navedeno da se mjerenje jednosmjernog efekta prisjetljivosti oblika može provesti na traci ili žici slitine CuAINiMn s prisjetljivosti oblika koja se savije za $90^{\circ}$ oko cilindra promjera $D$, slika 7 .

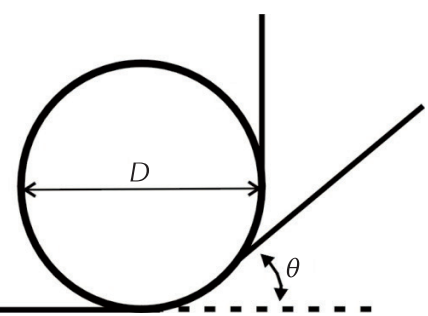

S I i k a 7 - Shematski prikaz mjerenja efekta prisjetljivosti oblika ${ }^{17}$ F i g 7 - Schematic illustration of shape memory effect measurement ${ }^{17}$

Za mjerenje oporavka, kao pokazatelja efekta prisjetljivosti oblika, savijeni uzorak zagrijava se u uljnoj kupki na $250{ }^{\circ} \mathrm{C}$. Deformacijsko istezanje $(\varepsilon)$ i oporavak oblika $(\eta)$ izračunaju se prema jednadžbama:

$$
\begin{aligned}
& \varepsilon=(\mathrm{c} / D+\mathrm{c}) \cdot 100 \% \\
& \eta=\left(90^{\circ}-\theta\right) / 90^{\circ} \cdot 100 \%,
\end{aligned}
$$

gdje je $\theta$ kut otklona, $c$ je debljina uzorka i $D$ je promjer cilindra koji se primjenjuje za test savijanja.

Z. Li et al. ${ }^{16}$ navedenom su metodom proučavali efekt prisjetljivosti oblika na slitini CuAINiMn dimenzija $20 \mathrm{~mm} \times$ $2 \mathrm{~mm} \times 0,5 \mathrm{~mm}$ koja je bila $10 \mathrm{~min}$ homogenizirana na $850{ }^{\circ} \mathrm{C}$ te hlađena u vodi. Nakon savijanja vrpce za $90^{\circ} \mathrm{sli}-$ tina je stavljena u kipuću vodu na 40 sekundi i zatim je izmjeren kut $\theta$. Uočeno je da i nakon 100 ciklusa deformacije i oporavka, oporavak oblika, $\eta$, iznosi 100 \%, slika 8 .

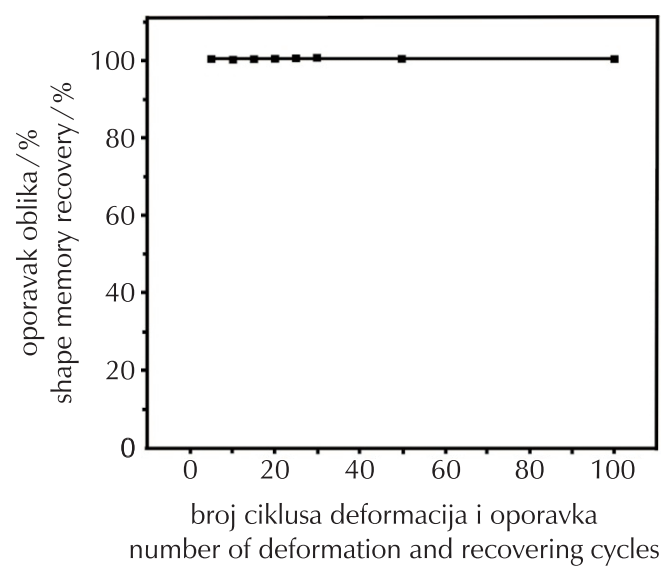

S I i k a 8 - Promjena oporavka oblika (n) ovisno o broju ciklusa deformacije i oporavka ${ }^{16}$

F i g . 8 - Change of the shape memory recovery ( $\eta$ ) as a function of deformation and recovering cycling ${ }^{16}$

\section{Dvosmjerni efekt prisjetljivosti oblika}

Kod jednosmjernog efekta prisjetljivosti oblika slitina "zapamti" samo oblik austenitne faze. ${ }^{6}$ Dvosmjerni efekt prisjetljivosti oblika omogućuje da slitina mijenja svoj oblik tijekom toplinskih ciklusa (zagrijavanja i hlađenja), između visokotemperaturnog i niskotemperaturnog oblika, slika 9. Unutarnje elastično naprezanje pokretačka je sila niskotemperaturnog oblika. Kako bi slitina mogla "zapamtiti" oba oblika, slitinu je potrebno "naučiti" željenom obliku, tj. potrebno je izvršiti "trening" slitine. ${ }^{3}$

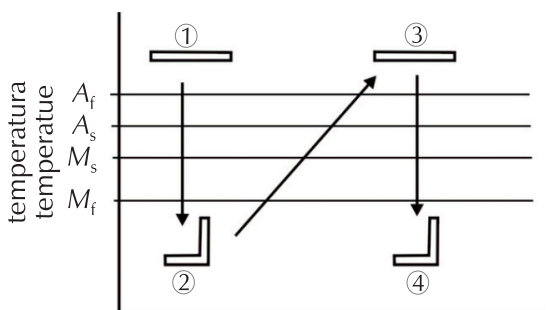

S I i k a 9 - Shematski prikaz dvosmjernog efekta prisjetljivosti oblika ${ }^{3}$

Fig. 9 - Schematic illustration of two-way shape memory effect ${ }^{3}$

Međutim problem se javlja kada se slitina s prisjetljivosti oblika s dvosmjernim efektom podvrgne vrlo malom stupnju naprezanja. Rezultat toga je značajno pogoršanje dvosmjernog efekta prisjetljivost oblika. Stoga je jednosmjerni efekt prisjetljivosti oblika još uvijek najkorišteniji efekt. ${ }^{15}$ 
Dvosmjerni efekt prisjetljivosti oblika slitine može se dobiti na dva načina. Prvi način je termomehaničko cikliranje (tzv. trening), gdje slitina "pamti" oblik visokotemperaturne i niskotemperaturne faze, te promjenom temperature dolazi do promjene oblika. Drugi oblik je stabilizacija naprezanjem induciranog martenzita (metoda "treninga" u jednom ciklusu), gdje se prate precipitati $\gamma$-faze i deformacijsko polje koje nastaje/nestaje oko njih tijekom promjene temperature. ${ }^{18,19}$

A. C. Kneissl et al. ${ }^{20}$ proveli su "trening" na trima različitim slitinama (NiTi, NiTiW i CuAINi) u obliku žice. Na slici 10 vidljivo je malo plastično (ireverzibilno) istezanje koje se inducira tijekom zagrijavanja i hlađenja (25 ciklusa) pri konstantnom opterećenju od 100 MPa. Zaključeno je da najveći dvosmjerni efekt prisjetljivosti oblika ima slitina NiTi u zakaljenom stanju (2,9\%). Dodatak volframa slitini NiTi značajno smanjuje dvosmjerni efekt prisjetljivosti oblika $(0,9 \%)$. Dvosmjerni efekt prisjetljivosti oblika CuAINi slitina iznosio je 1,5\%, te se može smatrati da je slitina vrlo stabilna i u tom pogledu se može dugotrajno primijeniti. ${ }^{20}$

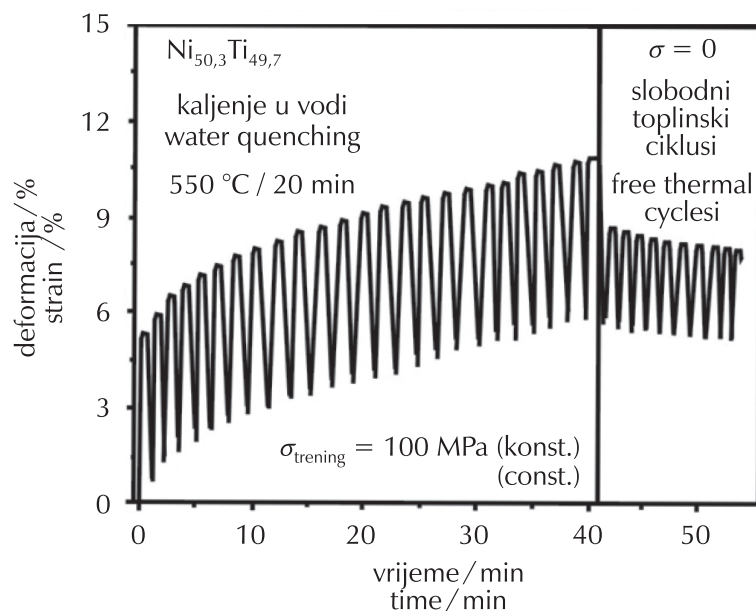

S I i k a 10 - Tijek deformacije tijekom treninga i tijekom slobodnih toplinskih ciklusa ${ }^{20}$

F i g . 10 - Course of strain during training and during free thermal cycles ${ }^{20}$

Drugi način dobivanja dvosmjernog efekta prisjetljivosti oblika stabilizacija je naprezanjem induciranog martenzita. Naprezanje kojim je podvrgnuta slitina uzrokuje usmjereni i orijentirani rast precipitata $\gamma$-faze u $\beta$-osnovi. Asimetrični rast martenzitne faze potpomaže nastajanju dvosmjernog efekta prisjetljivosti oblika bez prethodnog klasičnog procesa "treniranja" slitine. X. M. Zhang et al. ${ }^{15}$ u slitini CuZnAl utvrdili su postojanje velikog polja deformacije oko eliptičnih precipitata $\gamma$-faze u $\beta$-fazi te precipitate $\gamma$-faze okruglog oblika u martenzitu. Općenito se smatra da orijentirani precipitati $\gamma$-faze u $\beta$-fazi doprinose nastanku elastičnog deformacijskog polja u martenzitnim iglicama te poboljšavaju dvosmjerni efekt prisjetljivosti oblika. ${ }^{18,19}$

\section{Višestruki efekt prisjetljivosti oblika}

Razvojem slitina s prisjetljivosti oblika došlo je i do razvoja višestrukog efekta prisjetljivosti oblika. Ovaj efekt odnosi se na pojavu da nakon programiranja materijal s prisjetljivosti oblika ima jedan ili više međuoblika tijekom oporavka od trenutačnog do polaznog oblika. Poslije je dokazano da je višestruki efekt svojstvo svih polimera s prisjetljivosti oblika. ${ }^{15}$

\section{Superelastičnost, pseudoelastičnost i tzv. rubber-like ponašanje slitina $s$ prisjetljivosti oblika}

Pseudoelastična deformacija s naprezanjem induciranom transformacijom austenita u martenzit može se okarakterizirati kao superelastičnost. Pseudoelastičnost je elastična deformacija koja nestaje uklanjanjem naprezanja. Ponašanje slitine rubber-like je deformacija martenzita čija je osnova kretanje granica sraslaca koja je veća od stvarne elastične deformacije, ali još uvijek manja od pseudoelastične deformacije. $^{14}$

Superelastičnost i efekt prisjetljivosti oblika uglavnom su bili objašnjeni odvojeno, ali su to vrlo usko povezane pojave. Odnos između efekta prisjetljivosti oblika i superelastičnosti prikazan je na slici 11. Efekt prisjetljivosti oblika javlja se na temperaturama ispod $A_{s}$, zatim slijedi zagrijavanje iznad $A_{\mathrm{f}}$, dok se superelastičnost javlja iznad temperature $A_{\mathrm{f}}$ gdje je martenzit potpuno nestabilan u odsutnosti naprezanja. $U$ temperaturnom intervalu između $A_{\mathrm{s}}$ i $A_{\mathrm{f}}$ može postojati i efekt prisjetljivosti oblika i superelastičnost.

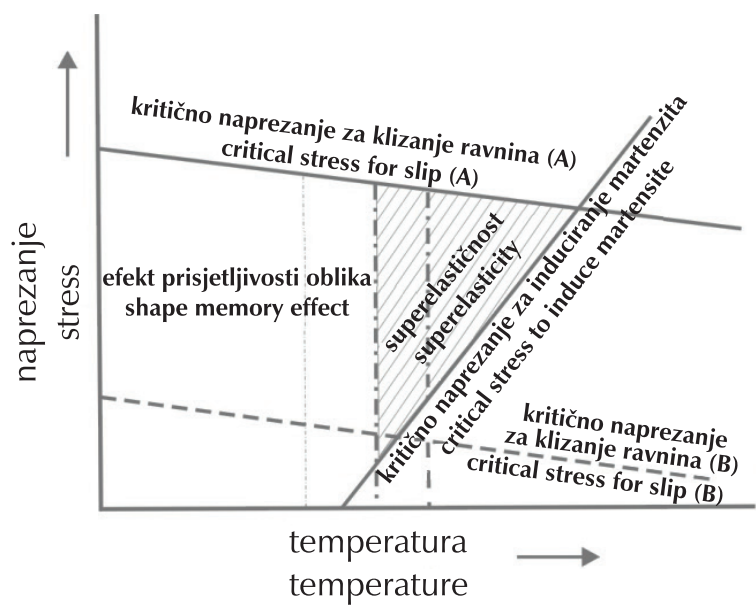

S I i k a 11 - Shematski prikaz područja efekta prisjetljivosti oblika $i$ superelastičnosti u ovisnosti o temperaturi i naprezanju ${ }^{6}$

F i g . 11 - Schematic diagram of the shape memory effect and superelasticity region in dependence of temperature and stress ${ }^{6}$

Pravac s pozitivnim koeficijentom smjera pokazuje kritično naprezanje koje je potrebno za induciranje martenzita (slika 11). Pravci s negativnim koeficijentom smjera (A i B) predstavljaju kritično naprezanje za klizanje. Osnovni uvjet za postizanje efekta prisjetljivosti oblika i superelastičnosti je kristalografski povratna martenzitna transformacija i izbjegavanje klizanja tijekom deformacije. ${ }^{6}$

\section{Zaključak}

Na temelju pregleda termomehaničkih svojstava najznačajnijih slitina s prisjetljivosti oblika može se zaključiti sljedeće:

- slitine s prisjetljivosti oblika slitine su s jedinstvenim svojstvom prisjetljivosti oblika, tj. pod određenim uvjetima vraćaju se u svoj prvobitni oblik

- karakteriziraju ih pseudoelastičnost, superelastičnost, po- 
našanje rubber-like i efekt prisjetljivosti oblika kao posljedica odvijanja martenzitne transformacije

- martenzitna transformacija je povratni kristalografski reorijentacijski proces između austenitne i martenzitne faze, te je ona ključna transformacija u slitinama s prisjetljivosti oblika

- jednosmjerni efekt prisjetljivosti oblika slitine "zapamti" samo oblik austenitne faze, dok slitina kod dvosmjernog efekta mora "zapamtiti" oblik visokotemperaturne austenitne i niskotemperaturne martenzitne faze, što se omogućuje "treningom" slitine.

- najveći utjecaj na pseudoelastičnost i efekt prisjetljivosti oblika imaju termomehanička obrada i naprezanje.

\section{Popis simbola i kratica List of symbols and abbreviations}

$$
\begin{aligned}
& A_{\mathrm{f}} \quad \text { - temperatura završetka austenitne transformacije, }{ }^{\circ} \mathrm{C} \\
& \text { - austenite transformation finish temperature, }{ }^{\circ} \mathrm{C} \\
& A_{\mathrm{s}} \quad \text { - temperatura početka austenitne transformacije, }{ }^{\circ} \mathrm{C} \\
& \text { - austenite transformation start temperature, }{ }^{\circ} \mathrm{C} \\
& \text { c - debljina uzorka, } \mathrm{mm} \\
& \text { - sample thickness, mm } \\
& \text { D - promjer, } \mathrm{mm} \\
& \text { - diameter, } \mathrm{mm}
\end{aligned}
$$

$\Delta G^{\mathrm{p} \rightarrow \mathrm{m}}$ - promjena Gibbsove energije austenitno-martenzitne transformacije, $\mathrm{J} \mathrm{mol}^{-1}$

- change of Gibbs energy of austenite to martensite transformation, $\mathrm{J} \mathrm{mol}^{-1}$

$M_{\mathrm{f}} \quad$ - temperatura završetka martenzitne transformacije, ${ }^{\circ} \mathrm{C}$ - martensite transformation finish temperature, ${ }^{\circ} \mathrm{C}$

$M_{\mathrm{s}} \quad$ - temperatura početka martenzitne transformacije, ${ }^{\circ} \mathrm{C}$

- martensite transformation start temperature, ${ }^{\circ} \mathrm{C}$

$t_{0} \quad$ - temperatura termodinamičke ravnoteže, ${ }^{\circ} \mathrm{C}$

- temperature of thermodynamic equilibrium, ${ }^{\circ} \mathrm{C}$

$\Delta t_{\mathrm{s}} \quad$ - pothlađenje potrebno za martenzitnu transformaciju, ${ }^{\circ} \mathrm{C}$

- undercooling necessary for martensite transformation, ${ }^{\circ} \mathrm{C}$

$\varepsilon \quad-$ deformacijsko istezanje, \%

- deformation strain, \%

$\eta \quad$ - oporavak oblika, \%

- shape memory recovery, \%

$\theta \quad$ - kut otklona vrpce, ${ }^{\circ}$

- deflection angle of the tape, ${ }^{\circ}$

A - austenit

- austenite

DM - naprezanjem inducirani martenzit

- stress induced martensite

$\mathrm{DM}_{\mathrm{k}}$ - naprezanjem inducirani martenzit (varijanta k)

- stress induced martensite (variant k)

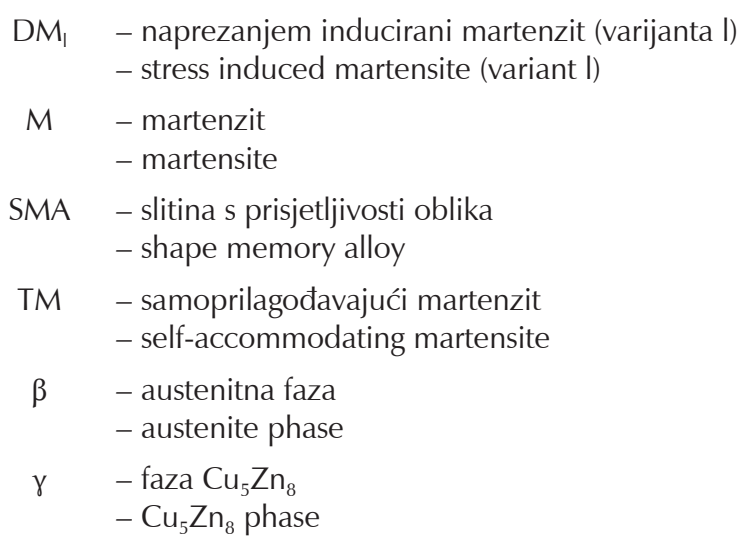

\section{Literatura \\ References}

1. D. E. Hodgson, Ming. H. Wu, R. J. Biermann, Shape Memory Alloys, ASM Handbook Volume 2: Properties and selection Nonferrous Alloys and Special-Purpose Materials, ASM Handbook Committee, 1992., str. 897-902.

2. M. Gojić, Alloys with the shape memory effects, Metalurgija (in Croatian) 31 (2-3) (1992), 77-82.

3. L. G. Machado, M. A. Savi, Medical applications of shape memory alloys, Braz. J. Med. Biol. Res. 36 (2003) 683-691, doi: http://dx.doi.org/10.1590/S0100-879X2003000600001.

4. K. Otsuka, X. Ren, Physical metallurgy of Ti-Ni-based shape memory alloys, Prog. Mater. Sci. 50 (2005) 511-678, doi: http://dx.doi.org/10.1016/j.pmatsci.2004.10.001.

5. D. Ćubela, Legure koje pamte svoj oblik, Mašinstvo 2 (6) (2002) 83-92.

6. K. Otsuka, C. M. Wayman, Shape memory materials, University of Cambridge, Cambridge, 1998.

7. H. Funakubo, Shape memory alloys, Gordon and Breach Science Publishers, New York, 1987.

8. D. Achitei, P. Vizureanu, N. Cimpoeşu, D. Dană, Thermo-mechanical fatigue of $\mathrm{Cu}-\mathrm{Zn}-\mathrm{Al}$ shape memory alloys, The $44^{\text {th }}$ International Conference on Mining and Metallurgy, Bor, Serbia, 2012., str. 401-404.

9. M. Čolić, R. Rudolf, D. Stamenković, I. Anžel, D. Vučević, M. Jenko, V. Lazić, G. Lojen, Relationship between microstructure, cytotoxicity and corrosion properties of a Cu-Al-Ni shape memory alloy, Acta Biomater. 6 (2010) 308-317, doi: http:// dx.doi.org/10.1016/j.actbio.2009.06.027.

10. J. Van Humbeeck, L. Delaey, A comparetive review of the (Potential) Shape Memory Alloys, ESOMAT 1989 - I $^{\text {st }}$ European Symposium on Martensitic Transformations in Science and Technology, Bochum, Germany, 1989., str. 15-26.

11. E. Patoor, D. C. Lagoudas, P. B. Entchev, L. C. Brinson, X. Gao, Shape memory alloys, Part I: General properties and modeling of single crystals, Mech. Mater. 38 (2006) 391-429, doi: http://dx.doi.org/10.1016/j.mechmat.2005.05.027.

12. L. Sun, W. M. Huang, Z. Ding, Y. Zhao, C. C. Wang, H. Purnawali, C. Tang, Stimulus-responsive shape memory materials: A review, Materials and Design 33 (2012) 577-640, doi: http:// dx.doi.org/10.1016/j.matdes.2011.04.065.

13. D. Stoeckel, The Shape Memory Effect - Phenomenon, Alloys and Applications, Conference Proceedings: Shape Memory Alloys for Power Systems EPRI, 1995., str. 1-13.

14. G. Lojen, I. Anžel, A. Kneissl, A. Križman, E. Unterweger, B. Kosec, M. Bizjak, Microstructure of rapidly solified Cu-Al-Ni 
shape memory alloy ribbons, J. Mater. Process. Tech. 162163 (2005) 220-229, doi: http://dx.doi.org/10.1016/j.jmatprotec.2005.02.196.

15. W. M. Huang, C. L. Song, Y. Q. Fu, C. C. Wang, Y. Zhao, H. Purnawali, H. B. Lu, C. Tang, Z. Ding, J. L. Zhang, Shaping tissue with shape memory materials, Adv. Drug Deliver. Rev. (2012), doi: http://dx.doi.org/10.1016/j.addr.2012.06.004.

16. Z. Li, Z. Y. Pan, N. Tang, Y. B. Jiang, N. Liu, M. Fang, F. Zheng, $\mathrm{Cu}-\mathrm{Al}-\mathrm{Ni}-\mathrm{Mn}$ shape memory alloy processed by mechanical alloying and powder metallurgy, Mat. Sci. Eng. A 417 (2006) 225-229, doi: http://dx.doi.org/10.1016/j.msea.2005.10.051.

17. Z. Xiao, Z. Li, M. Fang, S. Xiong, X. Sheng, M. Zhou, Effect of processing of mechanical alloying and powder metalurgy on microstructure and properties of Cu-Al-Ni-Mn alloy, Mat. Sci.
Eng. A 488 (2008) 266-272, doi: http://dx.doi.org/10.1016/j. msea.2007.11.037.

18. X. M. Zhang, M. Liu, J. Fernandez, J. M. Guilemany, Effect of small precipitates on the two-way shape memory effect in Cu.Zn-Al alloys, Materials and Design 21 (2000) 557-559, doi: http://dx.doi.org/10.1016/S0261-3069(00)00019-4.

19. J. Fernandez, X. M. Zhang, J. M. Guilemany, A one-cycle training technique for cooper-based shape memory alloys, J. Mater. Process. Tech. 139 (2003) 117-119, doi: http://dx.doi. org/10.1016/S0924-0136(03)00191-2.

20. A. C. Kneissl, E. Unterweger, M. Bruncko, G. Lojen, K. Mehrabi, H. Scherngell, Microstructure and Properties of NiTi and CuAINi Shape Memory Alloys, Metalurgija 14 (2008) 89-100. URL: $\quad$ http://www.metalurgija.org.rs/mjom/vol14/No\%20 2/2KNEISSL.pdf (2. 1. 2013.).

\title{
EXTENDED ABSTRACT \\ Shape Memory Alloys (Part I): Significant Properties
}

I. Ivanić, ${ }^{*}$ M. Gojić, and S. Kožuh

\begin{abstract}
Shape memory alloys (SMAs) belong to a group of functional materials with the unique property of "remembering" the shape they had before pseudoplastic deformation. Such an effect is based on crystallographic reversible thermo-elastic martensitic transformation. There are two crystal phases in SMAs: the austenite phase (stable at high temperature) and the martensite phase (stable at low temperature).

Austenite to martensite phase transformation can be obtained by mechanical (loading) and thermal methods (heating and cooling). During martensitic transformation, no diffusive process is involved, only inelastic deformation of the crystal structure. When the shape memory alloy passes through the phase transformation, the alloy transforms from high ordered phase (austenite) to low ordered phase (martensite). There are two types of martensite transformations. First is temperature-induced martensite, which is also called self-accommodating (twinned) martensite. The second is stress-induced martensite, also called detwinned martensite. The entire austenite to martensite transformation cycle can be described with four characteristic temperatures: $M_{\mathrm{s}}-$ martensite start temperature, $M_{\mathrm{f}}$ - martensite finish temperature, $A_{\mathrm{s}}$ - austenite start temperature, and $A_{\mathrm{f}}$ - austenite finish temperature. The main factors influencing transformation temperatures are chemical composition, heat treatment procedure, cooling speed, grain size, and number of transformation cycles.
\end{abstract}

As a result of martensitic transformation in SMAs, several thermomechanical phenomena may occur: pseudoelasticity, shape memory effect (one-way and two-way SME) and rubber-like behavior. Pseudoelasticity occurs when the SMA is subjected to a mechanical loading at a constant temperature above $A_{\mathrm{f}}$ The second thermomechanical behaviour that can be observed in SMA is the shape memory effect (SME), mainly one-way SME, which is the most commonly used SME. When the sample is subjected to a mechanical loading, the stress reaches a critical value and the transformation of twinned martensite into detwinned martensite begins and finishes when the loading process is finished. When the loading-unloading process is finished, the SMA presents a residual strain recoverable by alloy heating, which induces the reverse phase transformation. As a result, the alloy recovers to its original shape.

In this paper, a review of thermomechanical properties of shape memory alloys and general characteristics of martensite transformations is shown.

Faculty of Metallurgy, University of Zagreb

Received July 29, 2013

Aleja narodnih heroja 3

44103 Sisak, Croatia

Accepted November 29, 2013 
